\title{
MAURO RESTIFFE
}

Mais do que simples registros documentais de arquitetura, o trabalho fotográfico de Mauro Restiffe ganhou destaque ao longo dos anos pela interpretação dos espaços que o artista paulista apresenta em seus trabalhos. São famosas séries como Empossamento, de 2003, em que Restiffe retratou a "desestabilização da arquitetura" de Brasília durante a cerimônia de posse do primeiro mandato do ex-presidente Lula e a consequente interação da população com a cidade. Ou mais recentemente, Obra, em que registrou a reforma e transformação do antigo prédio do Detran no atual Museu de Arte Contemporânea da USP. Agora, no Centro Universitário Maria Antonia, Mauro apresenta fotografias das séries Vertigem e Warchavchik, que juntas formam a mostra Interseção.

O primeiro conjunto de fotos diz respeito à Casa Serralves, construção portuguesa projetada pelo arquiteto Jacques Gréber e executada por José Marques da Silva em 1940, na cidade do Porto, em Portugal, onde hoje funciona um grande complexo cultural. Foi a partir de sua investigação na casa que se iniciou a aproximação do fotógrafo com o trabalho de Gregori Warchavchik . "Eu fiz essas imagens da Casa Serralves, mostrei para o José Lira (curador da mostra Warchavchik - metrópole, arquitetura) e a gente começou um diálogo sobre Warchavchik. Fizemos visitas ao [edifício] Cícero Prado e o trabalho foi acontecendo".

A série Warchavchik compõe-se de fotos internas e externas do Edifício Cícero Prado, explorando entre outras coisas, a interação da construção com a cidade de São Paulo.

Já Vertigem apresenta um aspecto pouco frequente ao trabalho de Mauro Restiffe: $\mathrm{o}$ artista alterou a orientação de algumas das imagens, rotacionando-as e gerando um aspecto quase labiríntico, inclusive, pela repetição de alguns elementos arquitetônicos do interior da residência. 


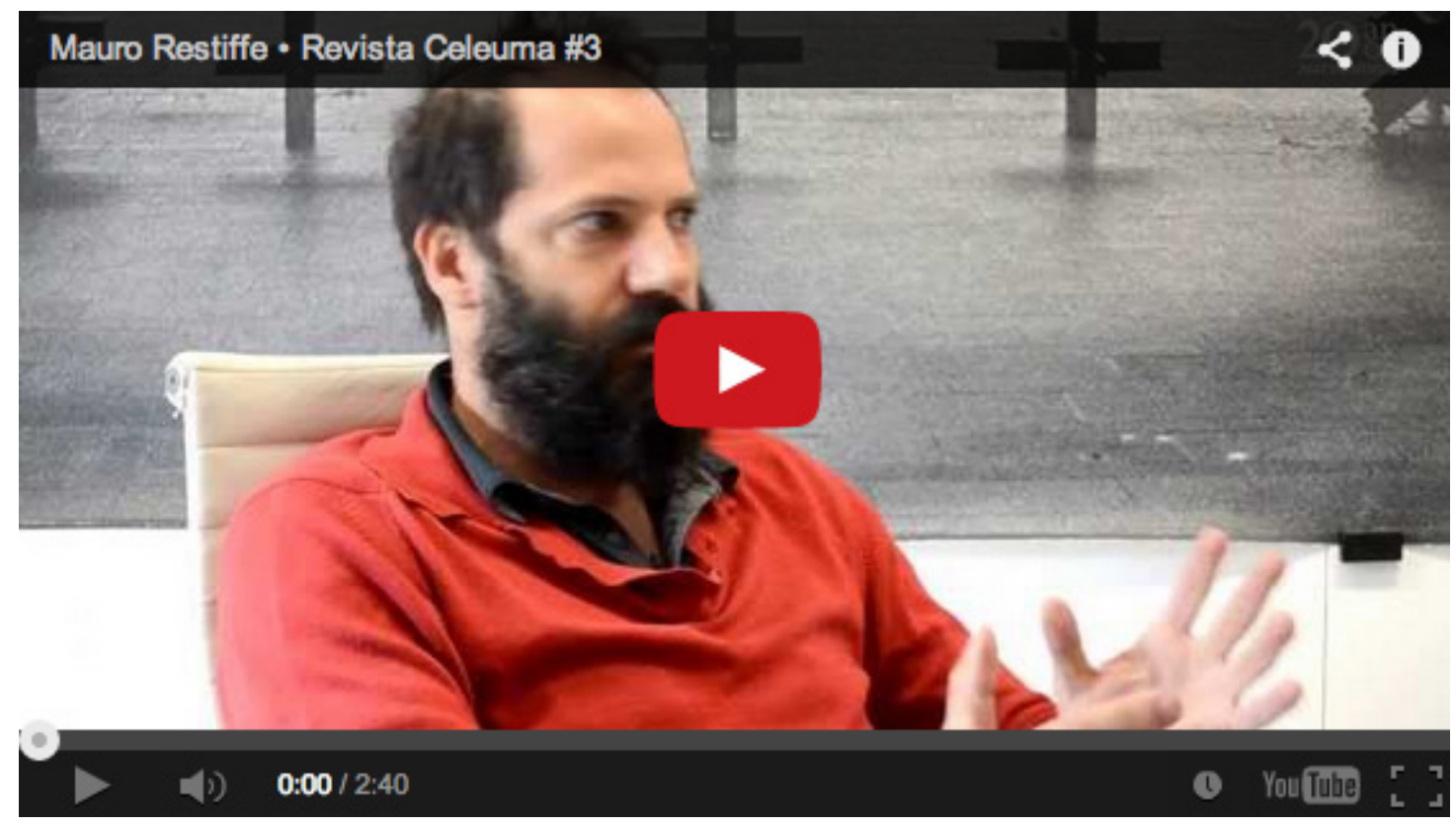

Para a realização das imagens, Mauro utilizou uma câmera de $35 \mathrm{~mm}$ e um filme de alta sensibilidade, que possibilita fotografar em ambientes com pouca luminosidade e dispensa o uso de tripé. O preto e branco dá continuidade a um estilo já estabelecido pelo artista: "o preto e branco traz a questão do meio fotográfico, no sentido de tentar manter uma tradição do analógico, pois remete a um deslocamento temporal ou uma certa atemporalidade. Para mim, o preto e branco é mais associado à interpretação, enquanto que uma gama maior de cores está mais associada à representação".

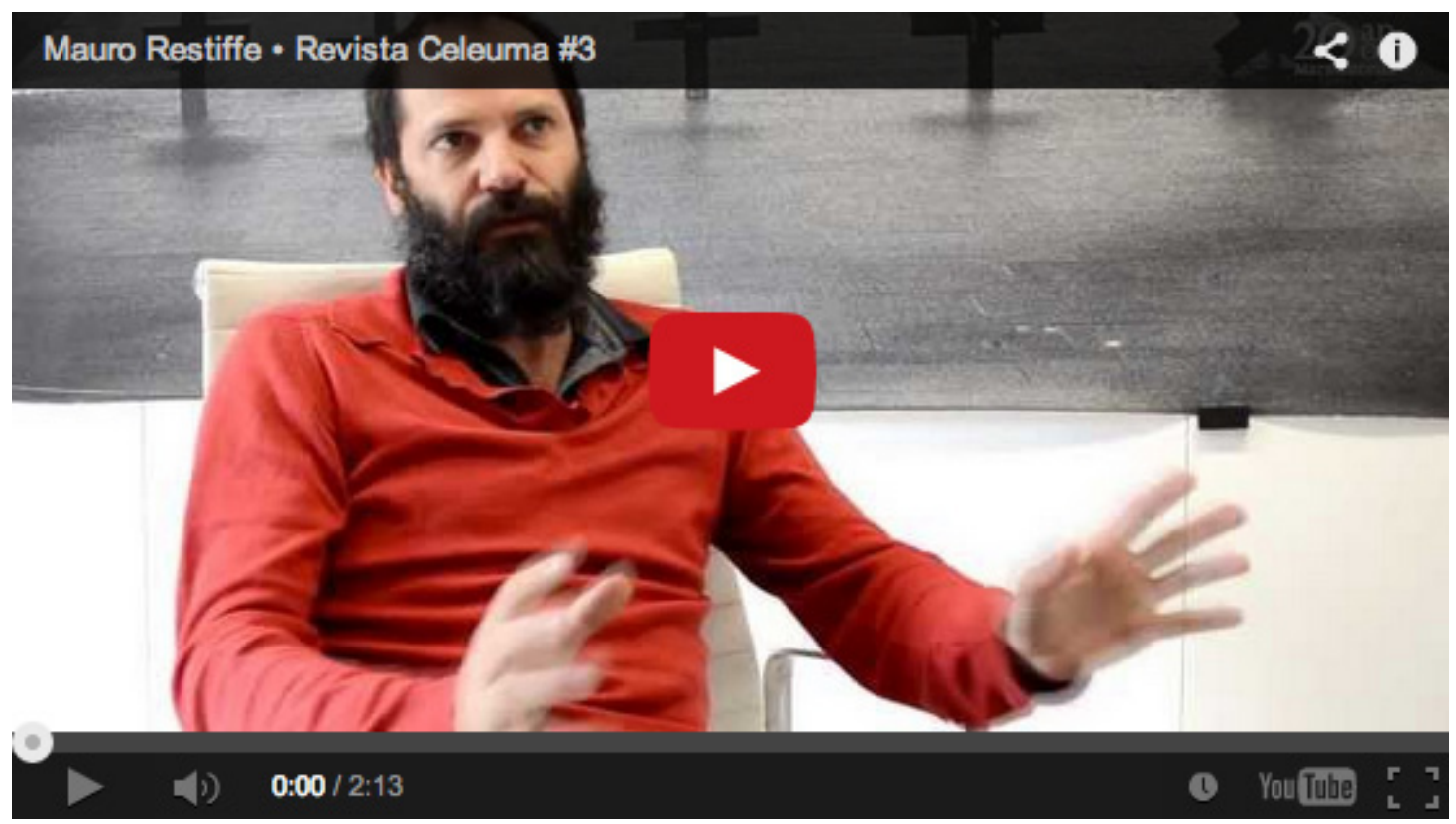


Finalmente, apesar da fotografia estar associada à vivência do fotógrafo com o local ou objeto fotografado, Mauro identifica a montagem como parte do processo: "o meu trabalho acaba se definindo de acordo com as circunstâncias de apresentação da imagem, de acordo com o espaço expositivo; e isso acaba definindo como essa imagem vai ser para resto da existência dela".

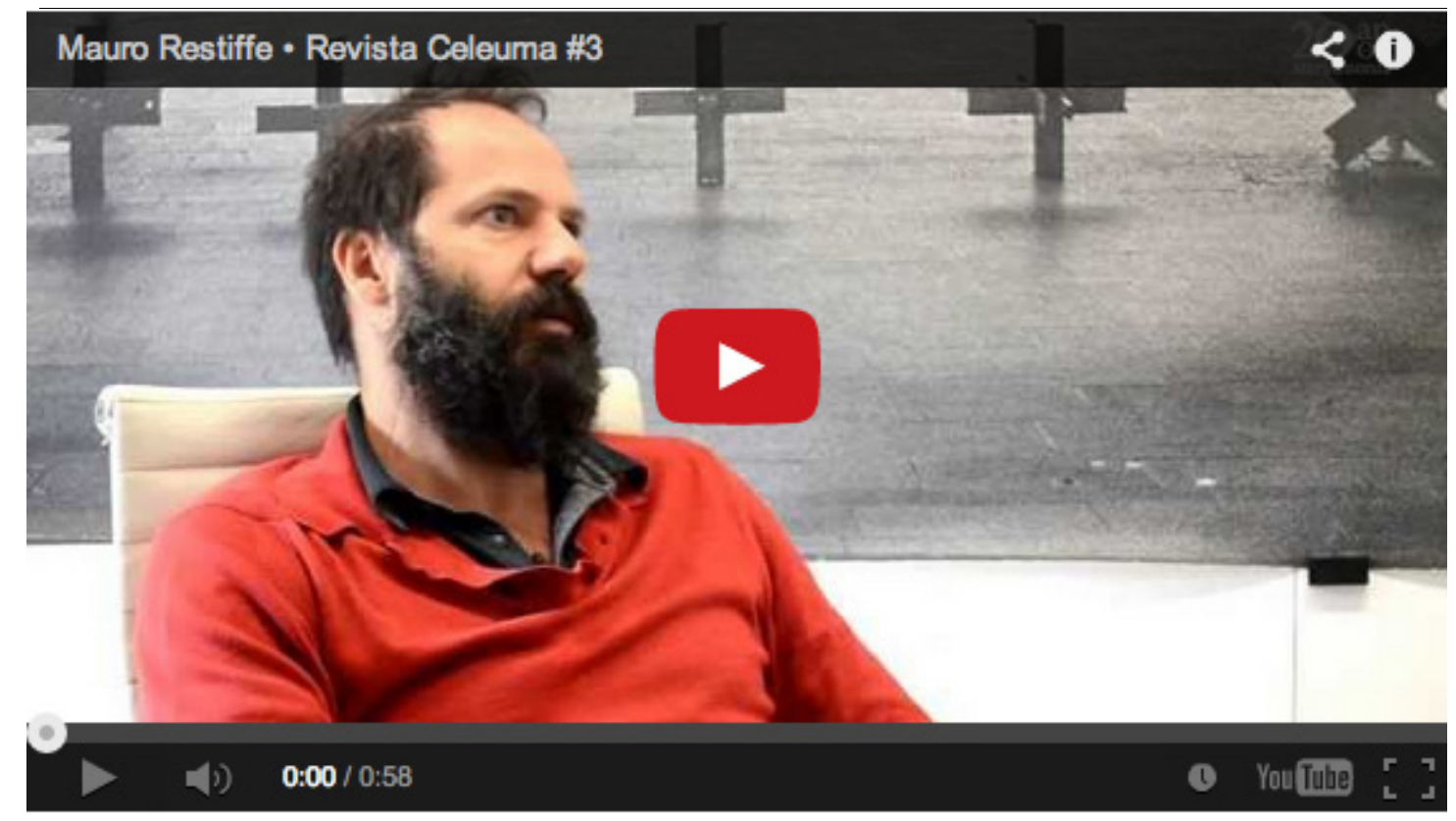

por Thierry Freitas. 